Journal of Engineering and Applied Sciences 15 (5): 1180-1189, 2020

ISSN: 1816-949X

(C) Medwell Journals, 2020

\title{
Rainwater Harvesting for Adaptation to Water Scarcity in Refugees Camps in Jordan
}

\author{
Naser Almanaseer \\ Department of Civil Engineering, Faculty of Engineering, \\ Al-Balqa Applied University, 19117 Al-Salt, Jordan
}

\begin{abstract}
This research aims at assessing technical, social and economic feasibility for the development and installation Rainwater Harvesting (RWH) as an adaptation option to water scarcity in Jerash refugees camp in Jordan. To achieve these goals, we investigated both engineering and socioeconomic aspects considering hydroclimatic and socioeconomic data. Further, expert panel of 22 experts across the country and over 15 stakeholders from the camp itself were properly consulted. Other parameters are considers including catchment area in terms of space and construction material. Different categories of rooftops are recognized in the camp ranging from metal sheet to concrete and from under $40 \mathrm{~m}^{2}$ in smaller shelters to over a $100 \mathrm{~m}^{2}$ in larger ones and public buildings such as schools and clinics. Another factors are the existing water supply systems in terms of quantity, quality and cost. For the water quality, water samples are collected from the existing domestic network, commercial filtered water and rainwater. In conclusion, RWH systems is technically and economically feasible and hence, it can be efficient and successful in the camp and in similar refugee camps across Jordan and therefore, water scarcity can be alleviated and the level of sanitation can be improved.
\end{abstract}

Key words: Rainwater harvesting, water, climate variability, water scarcity, hydrology, refugees, sanitation, feasibility, resilience, rooftop

\section{INTRODUCTION}

General: Considering the availability of water resources, Jordan suffers serious water shortage (Hadadin et al., 2010). However, the country made significant steps in the last few decades to improve water management policies, institutions and practices. Three of the most significant water management strategies adopted in Jordan include wastewater reuse, utilization of Disi aquifer and the initiation of the Dead-Red project (Salameh et al., 2018). Lately, the water national master plan, developed by the Jordanian Ministry of Water and Irrigation (MWI) introduced rainwater harvesting as a promising management strategy. Considering the precipitation intensity and distribution, rainwater is traditionally considered as a potential water resource that can be used to increase the per capita share and therefore, to ease water crisis in a given location (Salameh et al., 2018).

Rainwater harvesting techniques involve the collection and storage of rainwater and can be adopted to supplement domestic, irrigation and other water demands (AbdelKhaleq and Ahmed, 2007). In this study, the potential in rainwater harvesting will be evaluated at micro catchment scale i.e., rooftop in Jerash camp for domestic use. To evaluate the potential in rainwater harvesting in a given site, it is imperative to explore and evaluate alternative rainwater harvesting schemes and techniques and determine the opportunities of reducing the gap between supply and demand (Rahman et al.,
2014). Also, it is important to consider that climate variability and change have significant impact on water resources (Almanaseer and Sankarasubramanian, 2011) specially in terms of their quantity and quality (Almanaseer et al., 2012).

Previous studies and stakeholder consultations as well as field survey conducted in Jerash camp concluded that the access to sufficient drinking water as a serious challenge. In fact, this consideration is valid for many populations in Jerash camp, especially with the lack of proper water supply infrastructure and management. Preliminary interviews with local residents indicated that intermittent water supply cycles result in serious water quality problems such as corrosion during dry cycles. In fact, this corrosion causes partial blockage in the water supply network. On the other hand, different types of rooftops with wide range of area are observed in the camp. The metal sheet is dominant for smaller spaces while the concrete roofs are used for public buildings such as schools and health centers.

To sum up, RWHS are considered among the promising nonconventional water resources alternative management strategies, especially where other resources are considered scarce. A quick review of the climatic conditions over the governorate of Jerash and the surroundings indicates that there is a potential in adopting RWHS over the area of Jerash camp. For example, the annual rainfall recorded over Jerash exceeds $350 \mathrm{~mm}$ in most years leaves good opportunity for the collection and 
storing significant amount of water during wet season. However, the efficiency of the intended RWHS is highly dependent on several factors such as potential evapotranspiration, water quality, storage media and capacity and rooftop; material and construction specifications. Further, initial and running costs as well as maintenance are among the major concerns.

\section{Objectives:}

- Evaluate different solutions to water scarcity in Jerash camp

- Assess technical, social and economic feasibility for the development and installation of the Rainwater Harvesting System (RWHS) in Jerash camp

- Propose RWHS alternatives considering technical and economic parameters

\section{MATERIALS AND METHODS}

Approach: Several activities with proper methodologies are proposed to reach a set of research outcomes and therefore to achieve the overall objectives. The overall approach of this research considers a combination of both technical and socioeconomic data. This data, however are collected from reliable databases including MWI files and from the field as well. Further, the study benefited from previous projects in RWH over Jordan and abroad and from on-going UNRWA projects such as the urban planning activities. In fact, coupling the two types of data (technical and socioeconomic) is a key factor toward a successful assessment. Example technical data includes climatic variables such as rainfall patterns and distribution, potential evaporation, rainwater quality, sunshine duration and intensity. Similarly, socioeconomic data include income, water utility and energy costs. Other data includes rooftop area and material, existing storage media and capacity, availability of space for water storage, education and awareness levels related to RWH, social acceptance and most importantly willingness to cooperate and participate.

This research started with problem identification and preliminary data collection to develop a list of questions that need to be assessed. Based on the defined questions, a work plan with clear milestones and deliverables is prepared. The following steps are implemented:

- Problem identification

- Data collection and management

- Technical and socioeconomic data integration

- RWH alternatives development

Data collection and management: Data collected and managed to address the applicability of RWHS in terms of rainfall availability, rooftop material, awareness and level of cooperation, a single or shared rainwater harvesting approach. Further, the stainability and replicability these systems are assessed.

It is vital for a successful RWHS to understand the rainfall patterns over the targeted area in space and time (Rahman, 2018). In fact, understanding rainfall variability in space and time help quantify the amount of rain available for harvesting and support the optimization of the required storage capacity for domestic and agricultural purposes (Velasco-Munoz et al., 2019). Since, daily variations are considered very fine scale in such research and implementation problems, monthly data are analyzed to establish trends and to predict future variations in rainfall over the Jerash camp. Second, field survey to the camp are conducted to observe and identify the different types of micro catchments including rooftops, streets, common areas, yards, playgrounds and other spaces. In fact, two main types of rooftop materials are documented; metal sheets and concrete. Third, careful revision of previous and ongoing studies concerning the socioeconomic and environmental settings is conducted and socioeconomic information is gathered from reliable resources in coordination with the social worker and is further validated using bilateral meetings with residents in the camp. Fourth, water supply and demand per capita are estimated based on the technical and socioeconomic data, water deficit and surplus is identified and the potential in RWHS is assessed. Fifth, rainwater samples were taken from Jerash camp during the first and second rain storms this Winter and analyzed to ensure acceptability of water quality and to ensure tolerable level of public health and safety. Moreover, stakeholder consultation was conducted to have proper feedback from expert panel as well as residents on water supply and sanitation within the camp. Finally, a conceptual list of possible options for RWH alternatives; single or shared, privately owned or public buildings or a combination approach is assumed. More relevant details on data collection and management is presented in the following sections.

Hydroclimatology: In this section, the possibility of RWHS is mainly assessed based on hydroclimatic data. Since, its difficult to understand the variability in climatic conditions without understanding the surrounding circumstances this section describes Jersah catchment area as a whole with the focus on the Jerash camp. This section provides idea about topography, hydrologic characteristics and analyzes rainfall data versus evaporation.

Site description: Jerash catchment area is a part of Amman-Zarqa basin which is the most important groundwater resource in Jordan (El-Naqa and Al-Shayeb, 2009). Jerash catchment covers an area of $51 \mathrm{~km}^{2}$ and hosts the city of Jerash, Jerash camp and several towns. 
J. Eng. Applied Sci., 15 (5): 1180-1189, 2020

Table 1: Averages of the climatic parameters (2000-2018)

\begin{tabular}{|c|c|c|c|c|c|c|c|c|c|c|c|c|}
\hline Months & Jan & Feb & Mar & Apr & May & Jun & Jul & Aug & Sep & Oct & Nov & Dec \\
\hline Evaporation (mm) & 4.2 & 4.5 & 6.4 & 8.9 & 10.6 & 12.1 & 12.2 & 10.7 & 9.6 & 8.9 & 6.5 & 4.2 \\
\hline Max. temp $\left({ }^{\circ} \mathrm{C}\right)$ & 28 & 27 & 34 & 37 & 39 & 43 & 44 & 45 & 40 & 39 & 32 & 27 \\
\hline Min. temp $\left({ }^{\circ} \mathrm{C}\right)$ & -4 & -2 & -1 & 3 & 0 & 5 & 7 & 11 & 0 & 0 & -1 & -3 \\
\hline Mean temp $\left({ }^{\circ} \mathrm{C}\right)$ & 8 & 9 & 13 & 17 & 21 & 25 & 26 & 26 & 24 & 21 & 15 & 10 \\
\hline Wind velocity $\left(\mathrm{km} \mathrm{h}^{-1}\right)$ & 8.2 & 9.2 & 7.6 & 14.6 & 14.5 & 12.6 & 10.3 & 10.8 & 8.7 & 10.6 & 12.3 & 9.8 \\
\hline Sunshine duration (h) & 7 & 6 & 7 & 8 & 11 & 12 & 11 & 11 & 10 & 9 & 7 & 6 \\
\hline
\end{tabular}

Table 2: Annual rainfall information for the main stations in Jerash catchment area

\begin{tabular}{lccccc}
\hline Station & IDN* $^{*}$ & Area $\left(\mathrm{km}^{2}\right)$ & Dry & Wet & Average \\
\hline Ibbin & AD0018 & 5.41 & 280.9 & 823.7 & 483.6 \\
Jarash & AL0004 & 31.40 & 229.5 & 591.2 & 406.9 \\
Kitta & AL0005 & 9.94 & 341.1 & 792.4 & 398.56 \\
Prince Feisal Nursery & AL0036 & 2.36 & 194.5 & 475.3 & 36.3 \\
Qafqafa & AL0050 & 1.20 & 287.6 & 503.6 & 316.3 \\
\hline
\end{tabular}

Groundwater in this study area is exposed to heavy abstraction and to water quality deterioration due to urbanization over the recharge areas. Further, leaks from sewage system and from cesspools seems to tangibly worsen the water quality of groundwater and springs in the study area.

Topography and drainage: The general slope of Jerash catchment is from North to South. Elevations range from $1096 \mathrm{~m}$ above sea level at Tall Marqab to about $400 \mathrm{~m}$ below King Talal Dam. The average elevation of the catchment area is about $748 \mathrm{~m}$ above sea level. Thus, good amounts of rain during Winter season. There are several wadies draining the catchment area the main wadies being, Wadi Jerash, Wadi Souf, Wadi Tawahin, Wadi El-Gadir, Wadi Uweimir, Wadi El-Riyash, Wadi Nahia, Wadi Amama, Wadi Safar and Wadi Jadi. All of these wadies drain from North to South that is from the high land areas to the lowlands of the Jordan Valley. There are about 13 springs emerge in the study area of which five springs emerge from Hummar (A4) aquifer, six Springs from Na'ur (A1/2) aquifer and two springs from Kurnub $(\mathrm{K})$ aquifer. The average discharge of Springs ranges between $0.172 \mathrm{~m}^{3} / \mathrm{h}$ at Basset Abeid to $160 \mathrm{~m}^{3} / \mathrm{h}$ atEl-Birkatein. In addition, there are about 68 wells in the study area of which 26 wells penetrated Na'ur (A1/2) aquifer and 37 wells penetrated Kurnub (K) aquifer (Matouq et al., 2013) and (Salameh et al., 2018). The topography of Jerash camp is generally toward Southwest but it is obvious that the slope within the Jerash camp varies at smaller spatial scales due to the construction of roads, baths, shelters and other infrastructure. Hence, precise slopes; magnitude and direction must be determined for storm water harvesting.

Hydrology: Climate in general can be characterized as Mediterranean semi-arid with two distinct seasons; a long dry hot Summer season extending from May-September and a moderate Winter season extending from October-April. The climate of the catchment area in general and of the Jerash camp in particular is highly influenced by elevations. The Western part of the catchment which has elevations below $400 \mathrm{~m}$ above sea level has low precipitation and is dominated by hot dry weather. The Northern part of the catchment with elevations reaching $1096 \mathrm{~m}$ above sea level has high annual precipitation and frequent snow falls. However, the camp located at approximately $600 \mathrm{~m}$ above sea level and it represents the average climate conditions of the entire Jerash catchment.

Rainfall and evaporation: The average daily minimum temperature in the basin occurred in January is about $-4^{\circ} \mathrm{C}$ and about $36.25^{\circ} \mathrm{C}$ as an average daily maximum temperature Table 1 . The catchment as a whole is affected by dry wind in Summer, changes from East to Southeast and Southwest direction. In Winter, however, the catchment is affected by humid wind from West and Southwest. Generally, the Northwesterly wind is dominant in Summer and Southwesterly wind in Winter. The average daily wind speed is $10.8 \mathrm{~km} \mathrm{~h}^{-1}$. In general, wind speed for the long period (2000-2018) was ranging between 7.6 and $14.6 \mathrm{~km} \mathrm{~h}^{-1}$ Table 1 . The average daily relative humidity varies from $65.2-82.6 \%$ in Winter and from $59.2-71 \%$ in Summer.

Five weather stations are located in and around the catchment area. Based on climate data obtained from these stations the mean monthly rainfall distribution is found to be varied from one station to another according to topography, elevation and location. The rainfall in the catchment area occurs mostly in Winter months, October-May while the Summer months are completely dry and relatively hot. The precipitation data from the different rainfall stations for the period (2000-2018) are obtained from MWI. Precipitation data from the five rainfall stations are used to construct Thiessen polygon map for the catchment area in fact, one station is located inside the catchment and four are located in the surrounding of the catchment. Locations of the five stations are illustrated in Fig. 1. Table 2 shows the average rainfall of the main stations in the catchment for different water years' conditions. Further, Fig. 2 shows comparison between dry, normal and wet years at five rainfall stations in the study area. 


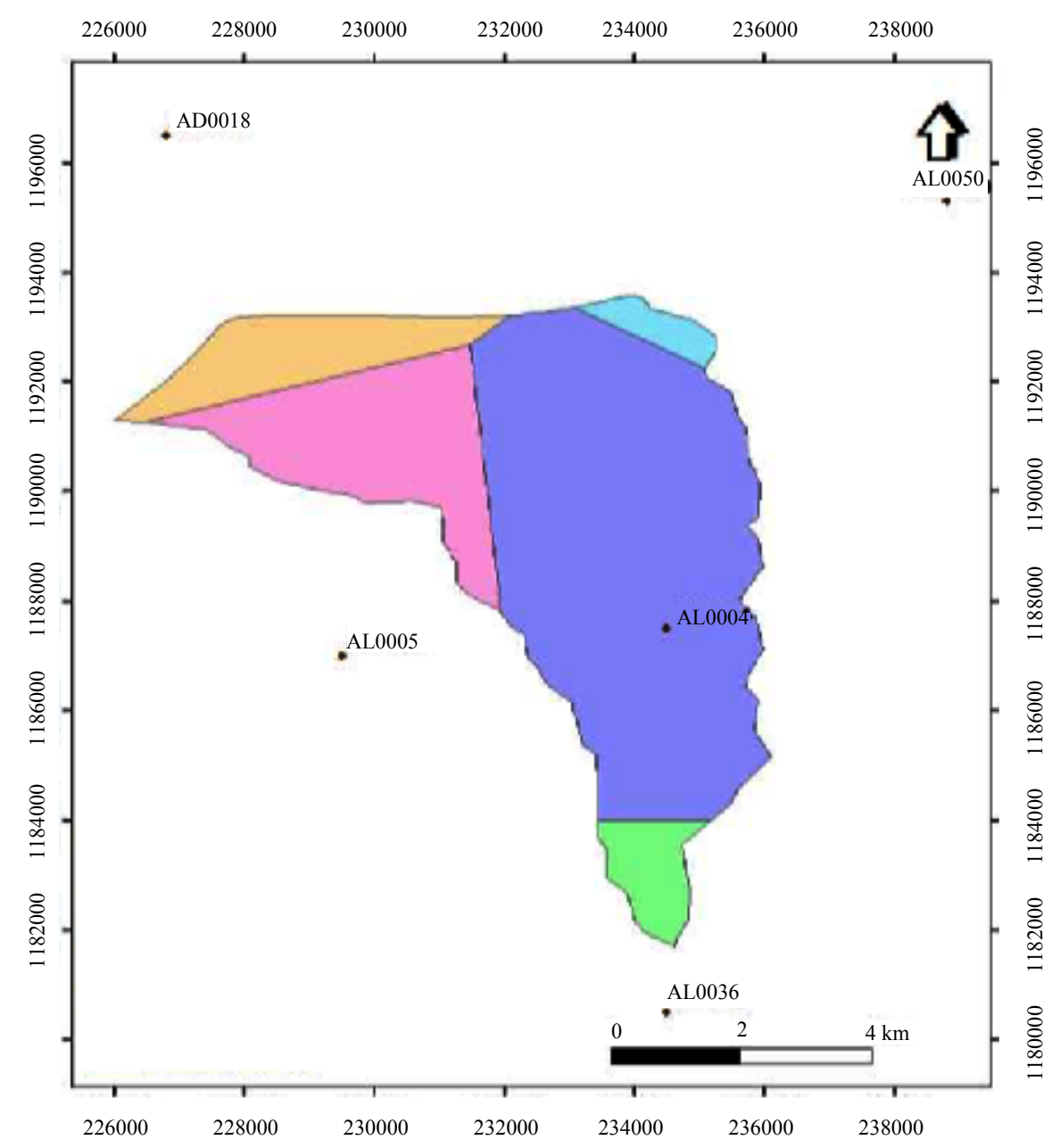

Fig. 1: Location of five rainfall stations in the study area with Thiessen polygon network

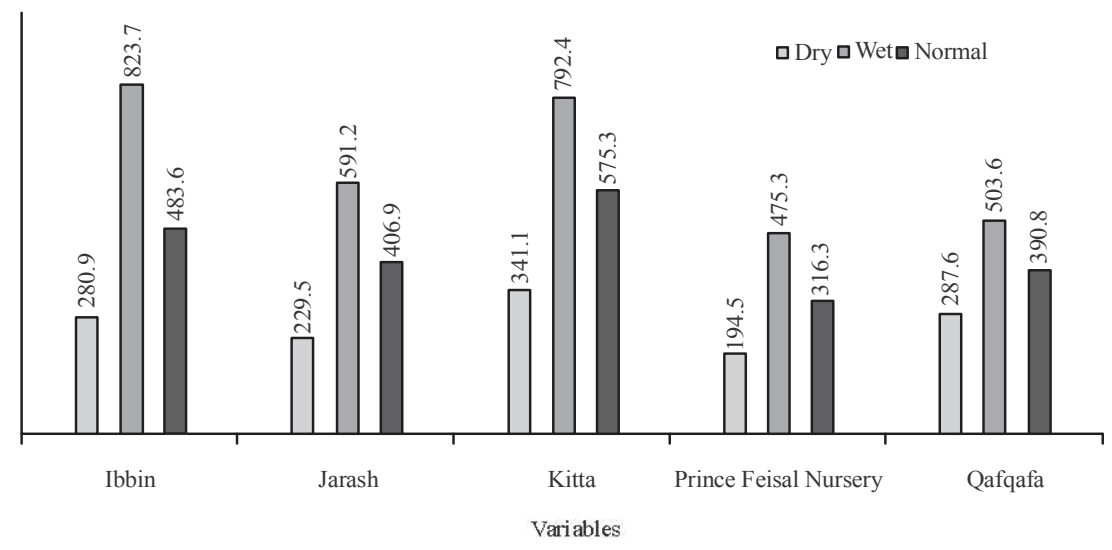

Fig. 2: Comparison between dry, normal and wet years at five rainfall stations in the study area

In conclusion, annual rainfall in governorate of Jerash is analyzed based on 10 years (2000-2018) of monthly rainfall data. It ranges between $304 \mathrm{~mm}$ in the Southern parts to $570 \mathrm{~mm}$ in the Northern parts. However, the average annual rainfall over Jerash camp during the period 2000-2018 is calculated as $398 \mathrm{~mm}$. Rainfall 
amounts for dry, normal and wet years are calculated over the same period as 230, 406 and 591, respectively. Quick evaluation of these figures emphasis on the fact that RWHS could be very successful in Jerash camp.

\section{RESULTS AND DISCUSSION}

Rainwater collection efficiency: In Jordan, RWH is one of the most important, reliable and socially accepted source of potable water for rural communities where there are no water supply networks. Even in some areas where potable water is supplied by networks, harvested rainwater is still a significant supplemental resource for domestic uses, especially, during Summer season when low quantity of water is available or supplied (Almanaseer and Sankarasubramanian, 2011). Currently, roof top rainwater harvesting in Jordan is being practiced for drinking water, domestic uses, livestock and for garden irrigation. Due to the importance of the collected rainwater, especially in arid areas, RWH and its quality are the central points of several ongoing researches at academic and implementation levels.

Based on the technical assessment of rainfall patterns over the period (2000-2018) the average annual rainfall over Jerash camp is calculated as $398 \mathrm{~mm}$. Considering the long-term average rainfall and the relatively low evapotranspiration rates during wet season, it is concluded with great deal of confidence that RWH is very applicable and reliable over the Jerash camp. However, the amount of rainfall is not the only criteria. For example, the adequacy of catchment area, availability of storage media and/or a space for a storage media, awareness level, participation and willingness to cooperate are all important aspects for a successful and sustainable RWH.

Therefore, it is important to integrate the socioeconomic conditions and characteristics with the climatic and other technical aspects of the area to develop a solid conclusion on the reliability of RWH that considers technical, social and economic variables to finally propose a list of RWH alternatives, provides preliminary designs for the proposed alternatives and finalizes the technical specifications and cost estimates for these RWH alternatives. To achieve these two major activities, design rainfall and rainfall collection efficiency are estimated, rooftop reliability and storage requirements are assessed and rainwater quality is examined and documented. Afterwards, RHW alternatives are suggested and described.

Design rainfall: Design rainfall is the annual amount of rainwater that is available for collection or the total annual rainfall minus the losses. In fact, design rainfall is the main factor that decides the economic and technical feasibility for any rainwater harvesting scheme. However, it is found that evaporation is playing a major role in the processes. For example, evaporation is highly correlated with mean monthly temperature and with sunshine duration Fig. 3, therefore, the hydroclimatic variables play a major role in the possible collected amounts of rainwater.

The average annual rainfall over Jerash camp is computed based on 20-years monthly data as $398 \mathrm{~mm}$ using Thiessen polygon network Fig. 1. Considering the average rainfall, rainfall amounts for dry, normal and wet years and taking into consideration the long-term evaporation rates over Jerash camp the rainwater available for collection is assessed as $90 \%$ of the total rainfall. Therefore, the design rainfall is estimated as $360 \mathrm{~mm} /$ year (Average annual rainfall $398 \mathrm{X}$ rainwater harvesting efficiency $90 \%=360 \mathrm{~mm} /$ year). The $90 \%$ efficiency assumes adequate catchment area that is clean and clear and have a slope of at least $2 \%$ to avoid any delay in the process of rainwater collection and hence, to reduce evaporation and other water losses.

Rooftops: Another important parameter is the rooftop in terms of area and material. Roof tops observed in the site are either metal sheet or concrete. For RWH purposes the existing rooftops that are made of metal sheets lake adequate design. For example, the slope is found not sufficient and the roof itself is not clear because it is often used as a storage space. Further, the rainwater cannot be collected at one point without catchment treatment and additional hardware modifications. To evaluate rainwater collection efficiency. Table 3 shows a comparison between metal sheets rooftops and concrete rooftops.

Storage requirement: Generally, storage media can be underground or above ground depending on the required storage capacity and on the available space as well. Underground pipe lines and cables could be a challenge for adopting underground storage media in shelter zones. However, in public building yards, it is possible to have underground storage media. Further, the assessment made based on site visits and interviews indicate the difficulty in having shared storage media due to possible social conflicts and water miss use. However, sharing storage within few shelters related to the same family is a possibility. Further, for any planned storage media, it is necessary to know that the cost for the construction ranges from hundreds to thousands USD depending on the design and capacity. Critical review of the existing storage media in Jerash camp shows that the investigated storage tanks were mostly above-ground tanks and made of either metal sheet or PVC. Tanks vary in their sizes from $1 \mathrm{~m}^{3}$ to slightly more than $2 \mathrm{~m}^{3}$. Some shelters use multiple tanks with a total storage ranging from $2-6 \mathrm{~m}^{3}$. However, larger public buildings have larger storagecapacities. Water can be easily extracted through a tap at the tank base and in limited cases by water pump. However, in some cases, tanks are installed on top of the buildings and the water is drained by gravity. 

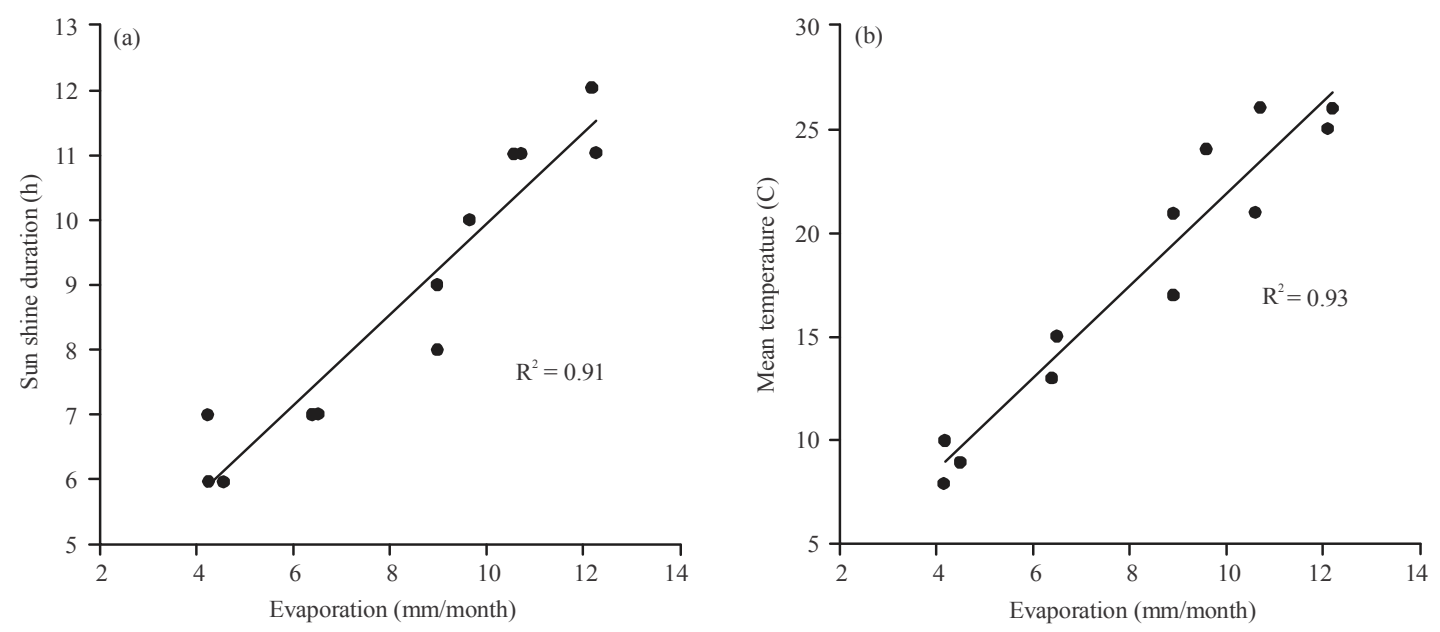

Fig. 3: Correlation of monthly evaporation with mean temperature and sunshine duration

Table 3: Comparison between rooftop types in Jerash camp

\begin{tabular}{lll}
\hline Parameters & Metal sheet & Concrete \\
\hline Area $\left(\mathrm{m}^{3}\right)$ & Under 80 & Above 80 \\
Use/Ownership & Residential/Private & Public/UNRWA \\
Catchment & Not clear/used as storage & Clear, except for water tanks \\
Slope & varies & Zero-5\% \\
Losses due to catchment type & High & Low \\
Losses due to evaporation rate & Under $10 \%$ & Under $10 \%$ \\
Existing storage & smaller & Larger \\
Rainwater quality & good & Good \\
Catchment treatment & Highly required & Not necessary \\
RWHS modifications & High & low \\
\hline
\end{tabular}

Water quality: Despite the continuous monitoring of public water supplies by governmental agencies, little is done for monitoring the rainwater quality. Nevertheless, rainwater is normally having minimal total dissolved solids that is far below the upper limits of drinking water standards. However, small particles of dust, sand and acids are normally washed down by rain, especially, during the very first storm in Winter and mainly in highly populated areas due to air pollution. On the other hand, rainwater is socially acceptable, especially, among groups with limited access to potable water. A unit of preliminary treatment can be installed at affordable cost but subject to effluent quantities. The larger the storage and collected rainwater the more feasible the treatment would be. For example, a large storage tank allows for natural settlement of silt and other objects in comparison to smaller PVC tank. Chlorination cost could be more viable for larger water amounts. Hence, and based on the requirement and feasibility of treatment, rainwater collection and storage from larger buildings would be more efficient.

In Jerash camp, a short-term rainwater quality assessment is conducted during the course of this study. To ensure the acceptability and sustainability of any proposed RWHS in terms of water quality, two samples are collected from domestic network and from filter water and compared to two samples collected from rainwater during the first storm and the second storm as well. Further, one sample is collected from direct rainfall is also considered to examine the impact of the rooftop material and/or any substances deposited on the rooftop in between the successive storms on the water quality of the collected rainwater. Further, the results of the analysis were compared to valid quality guidelines to evaluate its suitability. Overall, the analysis indicated a promising potential in adopting rainwater harvesting. Figure 4 shows the chemical analysis for the major cations and anions.

The analysis clearly indicates that the collected rainwater complies with the drinking water standards. In fact, the chemical constituents of the collected samples are less than those found in domestic water and very close to those found in filter water. To assess the possible impacts of the accumulated substances such as dust on the rooftops, direct rainwater sample is collected near the rooftop and compared to the sample from the rooftop. Direct rain shows a slightly better quality which suggests flushing the roof prior collection as a precaution measure. However, even rooftop sample itself is way better than the maximum limits and better than the domestic water as well and therefore, flushing is not really necessary in the second storm and after. 


\section{J. Eng. Applied Sci., 15 (5): 1180-1189, 2020}

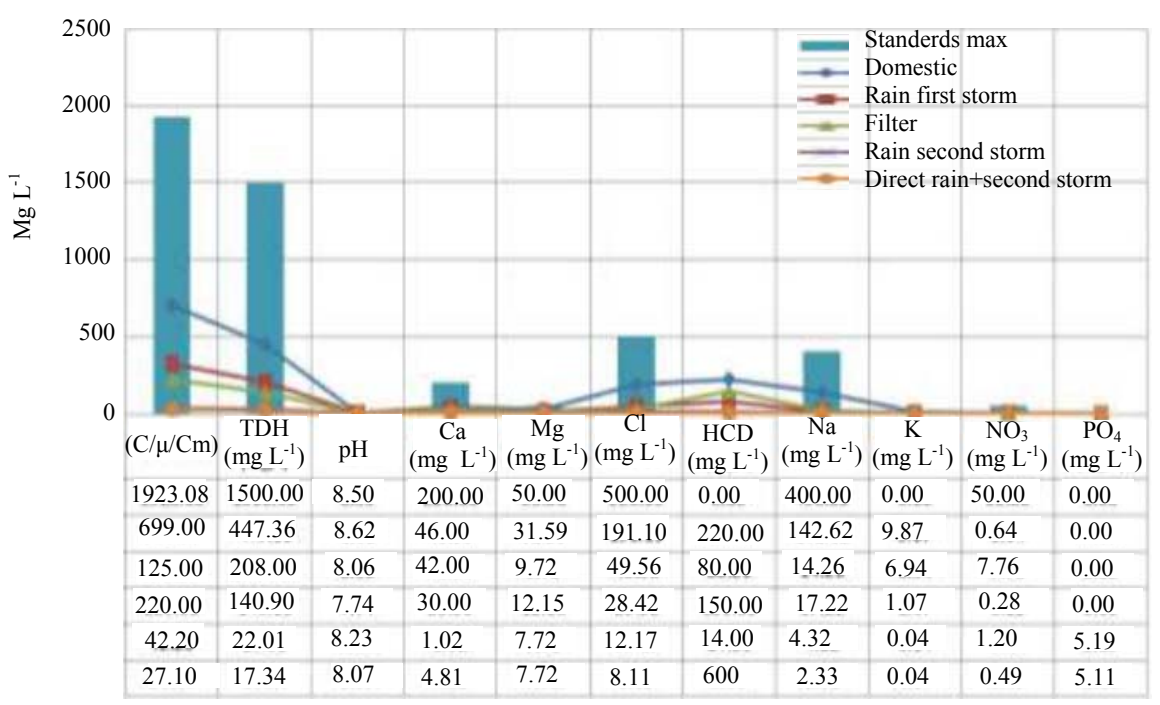

Fig. 4: Analysis for domestic, filter water and rainwater samples

Economic feasibility: The economic feasibility in this case can be simply evaluated by converting cubic meters of harvested water into dollar value. Considering a design rainfall of about $360 \mathrm{~mm} /$ year in any average year, a $1 \mathrm{~m}^{3}$ of proper catchment (with $90 \%$ collection efficiency) can harvest $0.36 \mathrm{~m}^{3}$ per year. That means shelters of 40 and $80 \mathrm{~m}^{2}$ can be prepared to harvest 14.4 and $28.8 \mathrm{~m}^{3}$, respectively.

Assuming a tankers rate of 3 USD per $1 \mathrm{~m}^{3}$ (this assumption is made based on interviews with selected residents in the camp through the study) the harvested water saved 43.2 and 86.4 USD for the above two shelters, respectively. However and when we consider a public building, a school for example, of $240 \mathrm{~m}^{2}$ concrete catchment area, about $86.4 \mathrm{~m}^{3}$ with a USD value of 259.2 can be collected and eventually saved.

A storage tank of reasonable capacity (normally $25 \%$ to $50 \%$ of the design rainfall) is required. The field survey indicated that the per capita consumption is only $100 \mathrm{~L}$ per day which is far below the national threshold of $120 \mathrm{~L}$ per capita per day. Considering a $100 \mathrm{~L}$ per capita per day a shelter of 5 residents will need $15 \mathrm{~m}^{3}$ per a month. On the other hand and for public buildings, even a larger storage is required and a water management system can be adopted and can be improved to distribute the water to nearby residents for drinking purposes during dry periods.

Since, the quality of rainwater is very good and is traditionally considered for drinking purposes only, it is recommended that the collected rainwater is stored in a separate tank to be used only for drinking purposes. In this case, the savings will be considerably worth adopting a successful RWHS. In fact, if we evaluate the collected water based on filter water (about 1 USD per $20 \mathrm{~L}$ ) the savings will be enormous. To be accurate, for shelters of 40 and $80 \mathrm{~m}^{2}$ that can be prepared to harvest 14.4 and $28.8 \mathrm{~m}^{3}$, respectively the annual savings will be 720 and 1440 USD for the two shelters, respectively.

RWHalternative systems: If the technical and economic of a water harvesting scheme is given then several socioeconomic factors are to be considered during the evaluation of the different RWHS alternatives. These factors include people priorities, people experience with RWHS, equity and gender issues, landownership, people participation, adoption and adaptation. For example, people priorities ranges from food safety, water safety, sanitation, independence and of course income. Hence, any proposed RWHS should meet the core of these aspects. However, the ability and willingness of people to participate is critical for the sustainability. Therefore, this study proposed several RWHS considering technical, economical but also present social factors and at planning, construction and operation stages. The suggested RWHS are considered the applicability and sustainability at individual, household and small community levels. Hence, the first RWHS is assumed for a single shelter (Alternative A) the second is for a multiple shelter (Alternative B) and the third is for apublic building (Alternative C). These three RWHS are categorized as privately owned or public. While there are different requirements and conditions for each alternative, common requirements should be met for any alternative. Common requirements include proper catchment area, availability for storage, adequate level of awareness and education, equity and gender issues, willingness to participate and experience with RWH. Table 4 and 5 provides brief description of three proposed alternatives. 
J. Eng. Applied Sci., 15 (5): 1180-1189, 2020

Table 4: RWHS alternatives description and evaluation

\begin{tabular}{|c|c|c|c|}
\hline Parameters & Alternative A & Alternative B & Alternative $\mathrm{C}$ \\
\hline Type & One shelter & (3-5 shelters) & Public building (s) \\
\hline Ownership & Private/single & Private/shared & Public/shared \\
\hline Catchment area $\left(\mathrm{m}^{2}\right)$ & $60-80$ & $240-400$ & $240-400$ \\
\hline Design rainfall $\left(\mathrm{m}^{3} /\right.$ year$)$ & $21.6-28.8$ & $86.4-144$ & 86.4-144 \\
\hline Proposed storage for rainwater $\left(\mathrm{m}^{3}\right)$ & $\begin{array}{l}2 \text { (small storage due to } \\
\text { limited spaces) }\end{array}$ & $\begin{array}{l}6-10 \text { (small storage due to } \\
\text { limited spaces) }\end{array}$ & $\begin{array}{l}\text { 6-10 (above ground) } \\
43.2-72.0 \text { (underground) }\end{array}$ \\
\hline $\begin{array}{l}\text { Theoretical savings (in US } \\
\text { Dollars assuming } 1 \text { USD for } 20 \mathrm{~L} \\
\text { based on filter water price) }\end{array}$ & $1080-1440$ & $4320-7200$ & $4320-7200$ (above ground) \\
\hline $\begin{array}{l}\text { Theoretical savings (in US } \\
\text { Dollars assuming } 5 \text { USD for } 1 \mathrm{~m}^{3} \\
\text { based on tankers price) }\end{array}$ & $108-144$ & $4320-7200$ & $4320-7200$ (above ground) \\
\hline $\begin{array}{l}\text { Actual savings in USD that can } \\
\text { be achieved assuming a } \\
\text { consumption of three times the } \\
\text { storage (because water is } \\
\text { consumed storm by storm) }\end{array}$ & $\begin{array}{l}2 \mathrm{~m}^{3} \mathrm{X}(1000 / 20) \\
\mathrm{X} 1 \mathrm{USD}=100 \\
\mathrm{USD}\end{array}$ & $300-500 \mathrm{USD}$ & $\begin{array}{l}300-500 \text { (above } \\
\text { ground) OR } 2160-3600 \\
\text { (underground and } \\
\text { filled once, not three times) }\end{array}$ \\
\hline $\begin{array}{l}\text { Cost for RWHS connections, } \\
\text { and roof modifications (USD) }\end{array}$ & 300 & $900-1500$ & $500-600$ \\
\hline Cost for catchment treatment (USD) & Depends on the case & Depends on the case & Depends on the case \\
\hline Cost for storage tank (USD) & 200 PVC or metal sheet & $600-1000$ (above ground PVC) & $\begin{array}{l}600-1000 \text { (above } \\
\text { ground PVC) OR } \\
5000-7500 \\
\text { (underground enforced } \\
\text { concrete) }\end{array}$ \\
\hline Water quality & Good & Good & Good \\
\hline Space required $\left(\mathrm{m}^{2}\right)$ & 3 & $4-10$ & $\begin{array}{l}4-10 \text { (above ground) } \\
\text { OR } 10-20 \text { (underground) }\end{array}$ \\
\hline Sharing & No & Yes & Yes \\
\hline Level of participation required & Good & Very good & Excellent \\
\hline Awareness level required & Good & Very good & Excellent \\
\hline Sustainability & Very good & Good & Excellent \\
\hline
\end{tabular}

Table 5: RWHS alternatives cost estimations

\begin{tabular}{llll}
\hline Parameters & Alternative A & Alternative B & Alternative C \\
\hline Total cost & 500 & 1500 for 3 shelters & 1100 or 1600 (above ground) \\
& & or 2500 for five shelters & 5500 and 8100 (underground) \\
Total savings assuming 1 USD for 20 L & 100 & 300 or 500 & 300 or 500 or $2160-3600$ \\
$\begin{array}{l}\text { Pay back (years) } \\
\text { Approximate number }\end{array}$ & 2 & 5 or 5 & 3.7 or 3.2 (above ground) 2.6 or 2.3 \\
of individuals served & 5 & 15 or 25 & Varies
\end{tabular}

of individuals served

RWH design: First of all, there are no well-defined standards or codes for rainwater harvesting design and installation in Jordan. However, any design should compile with municipal and civil and regulations. In this section, the feasibility study recommends preliminary term of references and guidelines for the design and installation of sufficient and functional rainwater harvesting collection and storage systems. The focus of these systems is to provide adequate amount of potable water based on the above mentioned alternatives.

Field visits to the camp shows that most shelters do not have the base foundations for installing rainwater harvesting collection systems. To be specific, roofs are not installed to fulfil certain requirements that are necessary for a successful rainwater harvesting schemes. For example, roofs are not clear has no sufficient slopes the direction and the orientation are also not compatible. On the other hand, public buildings (appear in the three pictures) show a good degree of suitability and have in deeded existing infrastructure such as smooth catchment, pipes and connections and barrels that can be easily modified to ensure efficient rainwater harvesting system. Following are three alternatives designs that describe the above mentioned three alternatives. Once the final decision is made on the type and number of rainwater harvesting systems, a detailed term of references will be drafted to ensure proper implementation of the selected pilots.

Single shelter: This option is very common, comes with very simple design, easy to install and more importantly easy to manage, operate and maintain. This design requires $60-80 \mathrm{~m}^{2}$ of catchment area, obviously rooftop that made of either concrete or metal sheets. Based on the average rainfall of about $400 \mathrm{~mm}$ per year and considering 10\% losses due to evaporation and splash, this design should be efficient to collect approximately $20-30 \mathrm{~m}^{3}$ depending on the size of the rooftop. The 
storage media is above ground PVC or metal tank with a capacity of at least $2 \mathrm{~m}^{3}$. The available space for a storage media is a determinant factor in this case. However, adding more storage units would highly improve the rainwater collection efficiency, especially, during heavy storms. Water quality is proven to be adequate for drinking purpose with minimal to no treatment.

Since, the study intend to guide the installation of rainwater harvesting systems on existing shelters, it is important that a screened gutter is attached to the existing roof top to collect and concentrate the rainwater. The system composed of nontoxic collection surface, screened gutter, non-metallic conveyance system, pre filter installed on the conveyance line, flush diverter normally used for diverting the first storm away for the storage tank and of course a storage tank. This design requires at least $3 \mathrm{~m}^{2}$ for each $2 \mathrm{~m}^{3}$ of storage

Multiple shelters: This system has a more complicated design in comparison to the single shelter. In fact, it is a multiple number of single shelters with the same specifications and design but with an extra collection system that collect the rainwater from the shelters and siphon it into one larger pipe to the storage media. The total space ranges from $240-400 \mathrm{~m}^{2}$ and the minimum required storage capacity would be $6-10 \mathrm{~m}^{3}$ depending on the size and number of the served shelters. The water quality is proven good but on simple filter might be needed to collect suspended solids prior storage facility. The proposed storage is above ground PVC tanks. A common area is needed to install the tanks and adequate level of awareness is required to manage, maintain and operate the rainwater collection system.

Public buildings: Public buildings can be a good environment for the collection, storage and more importantly sharing and managing rainwater. Based on field observations there are a series of multiple floors buildings with concrete rooftops, mainly UNRWA buildings such as schools and health centers. These buildings form a good rainwater harvesting collection and management option because it has the basic infrastructure including clear catchment, adequate slopes, pipes and more importantly a space is available for above and underground storage. Moreover these buildings provide sufficient catchment area that can easily ranges

from $240 \mathrm{~m}^{2}$ to more than $400 \mathrm{~m}^{2}$

The design will include catchment treatment to ensure smooth and clear catchment with adequate slope toward a collection point, collection pipe, filter and a storage facility. The storage facility can be above ground PVC tanks with $6-10 \mathrm{~m}^{3}$ capacity or underground concrete reservoir with $43.2-72.0 \mathrm{~m}^{3}$ capacity. The variations in storage capacity are due to the space availability and budget constraints.

\section{CONCLUSION}

In conclusion, rainwater harvesting is considered among the most efficient and feasibly water resources alternatives. It provides with preliminary treatment, reliable sources for potable water and it helps raise the awareness at household levels by encouraging them toward saving more water. In Jerash camp and based on the analysis of 18-years climatic data, it is concluded that there is a high technical feasibility and opportunity for rainwater collection. The average rate of about $400 \mathrm{~mm}$ per year is an encouraging figure, especially, over an area with limited evaporation rates during cold Winter.

This assessment recognized two distinct types of buildings; shelters with metal sheet rooftops and public buildings with concrete rooftops. Shelters are much smaller in comparison to public buildings. Hence, require smaller storage media and it is recommended to be above ground and not shared among neighbors. On the other hand, storage media for public building can be up to $100 \mathrm{~m}^{3}$ per building depending on the catchment area and can be used to supply drinking water for the neighborhood during dry season.

Awareness campaign is recommended, especially among the selected shelters and/or buildings where rainwater harvesting is to be implemented. And a pre-selection criterion for these buildings is to be discussed and finalized based on climatic, physical conditions and area of the rooftop, cost, income, health, gender and social factors. Streets and vacant lands are found to be not suitable for rainwater harvesting. However, storm water collection system can be implemented to reduce the risk of infrastructure failure, hazards and unfortunate accidents. But this might be out of the scope of this study.

Finally, we recommend a multiple pilot RWHS in both shelters and public buildings. The implemented pilots should be evaluated and monitored in terms of efficiency, people participation and involvement of women, willingness to contribute, water quality frequent analysis. Over all evaluation of the pilots can be used as base for further steps toward rainwater harvesting, collection and treatment. Further, a solar energy unit can be proposed to provide clean energy for water treatment and distribution in the case of public building pilot. And electronic wastes can be accepted from residents in exchange for clean potable water as a contribution from their side. In this fashion, the pilot will provide water and will alleviate the level of awareness and cooperation among the refugees.

\section{ACKNOWLEDGEMENT}

The researcher acknowledges the contribution of the project entitled "WASAR-water and sanitation solutions 
to refugees: two cases from Jordan and Palestine funded by the DUPC2: IHE Delft Partnership Program for water and development for their contribution to this research. Also, special acknowledgement goes to Al-Balqa Applied University for making its facilities and laboratories available to this research. Finally, the researcher acknowledges the cooperation of the Jerash refugee camp residents for their cooperation.

\section{REFERENCES}

AbdelKhaleq, R.A. and I.A. Ahmed, 2007. Rainwater harvesting in ancient civilizations in Jordan. Water Sci. Technol. Water Supply, 7: 85-93.

Almanaseer, N. and A. Sankarasubramanian, 2011. Role of climate variability in modulating the surface water and groundwater interaction over the Southeast United States. J. Hydrol. Eng., 17: 1001-1010.

Almanaseer, N., A. Sankarasubramanian and J. Bales, 2012. Improving groundwater predictions utilizing seasonal precipitation forecasts from general circulation models forced with sea surface temperature forecasts. J. Hydrol. Eng., 19: 87-98.

El-Naqa, A. and A. Al-Shayeb, 2009. Groundwater protection and management strategy in Jordan. Water Resour. Manage., 23: 2379-2394.
Hadadin, N., M. Qaqish, E. Akawwi and A. Bdour, 2010. Water shortage in Jordan-sustainable solutions. Desalin., 250: 197-202.

Matouq, M., T. El-Hasan, H. Al-Bilbisi, M. Abdelhadi, M. Hindiyeh, S. Eslamian and S. Duheisat, 2013. The climate change implication on Jordan: A case study using GIS and artificial neural networks for weather forecasting. J. Taibah Univ. Sci., 7: 44-55.

Rahman, A., 2018. Rainwater Harvesting: Quantity, Quality, Economics and State Regulations. MDPI, Basel, Switzerland, ISBN: 9783038427148 , Pages: 178.

Rahman, S., M.T.R. Khan, S. Akib, N.B.C. Din, S.K. Biswas and S.M. Shirazi, 2014. Sustainability of rainwater harvesting system in terms of water quality. Sci. World J., Vol. 2014. 10.1155/2014/ 721357

Salameh, E., M. Shteiwi and M. Al Raggad, 2018. Water Resources of Jordan: Political, Social and Economic Implications of Scarce Water Resources. Vol. 1, Springer, Berlin, Germany, ISBN: 9783319777481 , Pages: 154.

Velasco-Munoz, J.F., J.A. Aznar-Sanchez, A. Batlles-delaFuente and M.D. Fidelibus, 2019. Rainwater harvesting for agricultural irrigation: An analysis of global research. Water, Vol. 11, No. 7. $10.3390 / \mathrm{w} 11071320$ 